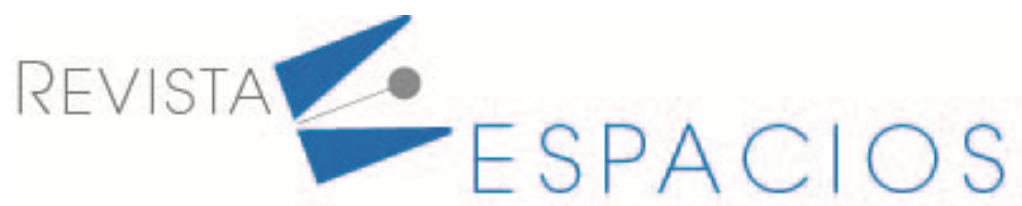

\title{
Ciencia abierta en América Latina: repensar la interdependencia dinámica entre las ciencias y la sociedad
}

\author{
Open science in Latin America: rethinking the dynamic interdependence between science \\ and society
}

\author{
MARTINOVICH Viviana ${ }^{1}$
}

\begin{abstract}
Resumen
A partir de repensar la noción mertoniana de "interdependencia dinámica" entre las ciencias y la sociedad, este texto se propone abordar dos procesos contrapuestos de las últimas décadas: mientras las políticas europeas ponen en cuestionamiento múltiples aspectos de la cultura científica industrial a través de la noción de ciencia abierta, en América Latina, se refuerzan nociones de impacto que ponderan las lógicas monopólicas que primaron durante la segunda mitad del siglo XX.

Palabras claves: ciencia abierta, cultura científica, industrialización de las ciencias, américa latina

Abstract

Starting from rethinking the Mertonian notion of "dynamic interdependence" between science and society, this text aims to address two opposing processes of recent decades: while European policies question multiple aspects of industrial scientific culture through notion of open science, in Latin America, notions of impact are reinforced that weigh the monopolistic logics that prevailed during the second half of the 20th century.

Keywords: open science, scientific culture, industrialization of sciences, latin america
\end{abstract}

\section{Introducción}

Desde el surgimiento de las ciencias modernas en el siglo XVII hasta la actualidad, la escritura, la publicación y, sobre todo, la puesta en circulación de sus textos ha permitido el diálogo público que las ciencias entablan en el plano narrativo, diálogo sobre el cual se han cimentado las distintas tradiciones y corrientes de pensamiento. Las disputas en las múltiples intermediaciones que operan desde la escritura de un manuscrito a su apropiación social, son tan solo una parte de las diversas dimensiones de la relación ciencias-sociedad, que ha tenido diversos matices traccionados por valores de la propia comunidad científica en relación con su entorno social y del valor que cada sociedad ha otorgado a las ciencias en términos históricos.

\footnotetext{
${ }^{1}$ Doctoranda en Salud Colectiva. Editora ejecutiva de la revista científica Salud Colectiva. Directora editorial de la colección de libros Cuadernos del ISCo. Docente-investigadora, Instituto de Salud Colectiva, Universidad Nacional de Lanús, Buenos Aires, Argentina
} 
En pleno proceso de industrialización de las ciencias, Robert Merton recupera como un valor propio del ethos científico la "propiedad común de bienes", es decir que los resultados de las ciencias son producto de la colaboración social y están destinados a la comunidad. Desde el estructural funcionalismo mertoniano, estos valores hacen que la noción de propiedad de la comunidad científica sea "incompatible con la definición de la tecnología como 'propiedad privada' en una economía capitalista” (Merton, 1964, p. 644).

Si bien estas tensiones en torno a la "propiedad" del conocimiento científico han tenido un nuevo capítulo a partir del movimiento de acceso abierto que surgió a fines del siglo XX (Willinsky, 2005), la actual noción de ciencia abierta pone el acento en otras dimensiones de la cultura científica, que tomaron expresiones sociales distintas en diversos momentos históricos, dada la "interdependencia dinámica" entre las ciencias y el contexto social (Merton, 1964). Si bien esta interdependencia puede resultar una obviedad, desde distintas disciplinas se han analizado las consecuencias de las ciencias sobre la estructura social, pero existe cierta resistencia a explorar esa relación en sentido bidireccional, es decir, incorporando "las diversas influencias de la estructura social sobre el ritmo de desarrollo, los focos de interés y, quizá, sobre el contenido mismo de la ciencia" (Merton, 1964, p. 617). Esa resistencia a admitir la influencia del entorno social sobre la práctica científica y sobre las formas de circulación y legitimación de la producción escrita, puede proceder, según Merton, de la creencia errónea de que asumir esa interdependencia implicaría la intromisión de intereses ajenos a las ciencias, y la pérdida de ciertos valores que conforman el ethos de la ciencia como la autonomía, la "objetividad", los criterios universales de validez científica y la propia universalidad del diálogo entre quienes comparten formas comunes de interpretación del mundo.

De forma similar, la historiadora estadounidense Elizabeth Eisenstein, describe esa misma resistencia vinculada a los procesos de intermediación de la producción escrita: la historia de las ciencias suele utilizar el material publicado en libros o en revistas científicas para documentar observaciones o teorías, sin incorporar las múltiples instancias mediadoras que participan del proceso de publicación y puesta en circulación como aspectos centrales de la existencia pública de una obra, por lo que "se desconecta la vida 'interna' de la ciencia de las fuerzas sociales externas que la moldearon desde su nacimiento" (Eisenstein, 2010, p. 607).

Si las revistas científicas son uno de los dispositivos centrales del sistema de comunicación de las ciencias ¿es posible analizarlas de forma aislada y desvincularlas de los procesos de configuración de la racionalidad técnica que motorizó la industrialización y moldeó las prácticas científicas? Si la universalidad del diálogo científico mantiene su total vigencia, ¿podemos analizar las revistas científicas de América Latina como un objeto de estudio aislado, cuando su comunidad está atravesada por valores que exceden sus fronteras? Entendemos esa interdependencia dinámica como parte de la dimensión relacional de la vida social y al segmentar y aislar analíticamente ciertos elementos puntuales, se pierden los marcos estructurantes de ciertos procesos y prácticas.

Partiendo de esta perspectiva, proponemos analizar cómo la ciencia abierta, en el contexto europeo, nace como reacción al proceso de industrialización de las ciencias y a la mercantilización de la producción escrita; y cómo la idealización de ese proceso, sumado a ciertos usos de las nociones de "universalismo" y de "autonomía", en muchos países de América Latina anularon la dimensión social y política tanto del ejercicio de la propia práctica científica como de su análisis, provocando la ausencia de políticas públicas soberanas y la adopción y naturalización de sentidos, imaginarios e idealizaciones que fueron elaborados a lo largo de tres siglos en otros escenarios (Hurtado, 2010). 
Si bien las ciencias abarcan una gran diversidad de concepciones y prácticas, en este trabajo nos centramos específicamente en aquellas áreas científicas vinculadas a los procesos de industrialización, que entendemos que estructuraron gran parte de la racionalidad científico-tecnológica que motorizó la expansión del capitalismo y los fundamentos de las políticas científicas. Tal como menciona Gadamer,

En la era de la ciencia y de su ideal de certeza, este concepto [la praxis] se ha visto despojado de su legitimidad, pues desde que la ciencia ve su objetivo en el análisis aislante de los factores causales del acontecer -en la naturaleza y en la historia-, ya no conoce otra praxis que la aplicación de la ciencia. Y ésta no necesita dar cuenta de su justificación. De este modo, el concepto de la técnica ha desplazado al de la praxis, o dicho de otro modo, la competencia del experto ha desplazado a la razón política. (Gadamer, 2005, p. 647)

Al anular la razón política tanto de la práctica de las ciencias, como del estudio de esas prácticas, la racionalidad técnica se torna en sí misma la racionalidad de la acción social. Habermas retoma las palabras de Marcuse al mencionar que "el concepto de razón técnica es quizá él mismo ideología", dado que se consolida sobre "un dominio metódico, científico, calculado y calculante" no solo sobre la naturaleza, sino también sobre las dimensiones sociales (Habermas, 2007, p. 55).

La técnica se torna así el proyecto histórico-social del capitalismo. El método científico que conducía a una dominación cada vez más eficiente de la naturaleza, proporcionó tanto los conceptos como los instrumentos para una dominación cada vez más efectiva de otras esferas sociales. "Hoy la dominación se perpetúa y amplía no sólo por medio de la tecnología, sino como tecnología; y ésta proporciona la gran legitimación a un poder político expansivo que engulle todos los ámbitos de la cultura" (Habermas, 2007, p. 58)

A partir de estas nociones, en este texto proponemos un breve recorrido, en primer lugar, por el proceso de industrialización de las ciencias europeas y la conformación del pensamiento científico liberal en América Latina; en segundo lugar, por el proceso de industrialización del sistema de comunicación de las ciencias; y, por último, por las recientes políticas europeas que ponen en cuestionamiento múltiples aspectos de la cultura científica industrial a través de la noción de ciencia abierta, en contraste a las políticas de América Latina, que refuerzan nociones de "impacto científico" que ponderan las lógicas que primaron durante la segunda mitad del siglo XX en los países industrializados.

\section{El proceso de industrialización de las ciencias europeas y la conformación del pensamiento científico liberal en América Latina}

El matemático e historiador de las ciencias irlandés John Bernal, en The social fuction of science (1939) describe un escenario científico altamente industrializado en la Europa de entreguerras: afirma que la producción con fines de lucro distorsiona inevitablemente la aplicación de la ciencia $y$, por ende, la orientación de la investigación; y que la competencia y el monopolio conducen directamente al "secreto" -patentamiento, leyes restrictivas de propiedad intelectual, etc.- y al empobrecimiento de la investigación. Según Bernal, una de las causas de la naturaleza peculiarmente poco imaginativa de la investigación industrial es su temperamento puramente comercial, que trata sus resultados como mercancías y a los productores de esos resultados como trabajadores asalariados.

La industrialización de las ciencias que describe Bernal en 1939 se produce por la incorporación de laboratorios de investigación y desarrollo (I+D) dentro de las industrias, como respuesta a la creciente complejidad y escala 
de las nuevas tecnologías que surgieron en las industrias eléctrica y química en la segunda mitad del siglo XIX, y que le permitieron a Alemania y EEUU desplazar a Gran Bretaña como líder tecnológico, en el período previo a la Primera Guerra Mundial (Freeman, 2010). Este nuevo engranaje para la consolidación de un "sistema nacional de innovación", según Christopher Freeman (2010), comprendía laboratorios universitarios y la introducción del doctorado como título de investigación, los laboratorios internos de I+D en los sectores líderes de la industria, instalaciones de control de calidad, institutos nacionales de normalización, institutos y bibliotecas nacionales de investigación, y una red de sociedades y publicaciones científicas y técnicas nacionales. Desde sus orígenes, eran las sociedades científicas y las editoriales universitarias las que editaban y promovían el intercambio de conocimientos a través de revistas científicas, cuya finalidad estaba más centrada en socializar las investigaciones que en el lucro (Fyfe et al., 2017).

En ese escenario, desde el siglo XIX hasta el primer tercio del siglo XX, América Latina fue "la proveedora de gran parte de las materias primas requeridas por la Revolución Industrial" (Jaguaribe, 2011), así como una gran fuente de abastecimiento de productos primarios agropecuarios. Para el ejercicio de esta economía primarioexportadora, el desarrollo de las ciencias vinculadas a la tecnología se centró en el desarrollo de formas eficaces de almacenamiento, conservación y transporte de esa producción primaria. Este modelo produjo el ingreso de capitales extranjeros que se destinaron a la extensión de las redes ferroviarias, la modernización de los servicios portuarios y el transporte marítimo, los frigoríficos, las comunicaciones telegráficas internacionales, al financiamiento de la producción primaria y la urbanización, lo que sumado al aumento de la población por la emigración europea, dio lugar a la conformación incipiente de un mercado interno dinámico (Belini, 2017).

Según Celso Furtado (1974), algunas de las consecuencias de este modelo fueron que los países exportadores de materias primas se transformaron rápidamente en importadores de nuevos bienes de consumo de los países industrializados, y gran parte de ese consumo podía ser absorbido por una minoría, dado que el aumento de la producción se asociaba a una mayor concentración de riquezas en minorías concentradas cuya capacidad de consumo crecía sustancialmente. Como la participación de las ciencias en la introducción de innovaciones en los procesos productivos fue mucho más acotada, era el Estado quien financiaba las sociedades científicas, universidades, museos y observatorios, de los que surgieron diversas revistas científicas, también financiadas por el Estado, que a través del sistema de "canje" de publicaciones, habilitaron un diálogo fluido con otras sociedades científicas del mundo.

Más allá de la fuente de financiamiento, a diferencia de los libros que históricamente fueron editados, distribuidos y comercializados por personas y entidades dedicados a la actividad editorial, en el caso de las revistas científicas de América Latina, al igual que las revistas europeas, estaban editadas por personas dedicadas a alguna rama de las ciencias, bajo el respaldo de instituciones académicas (sociedades científicas, universidades, observatorios, etc.).

Como describe Habermas (2007), "hasta fines del siglo XIX no se registra una interdependencia de ciencia y técnica" y el aporte de las ciencias al proceso de modernización es más bien indirecto, por lo que parecería haber una cierta sintonía en el pensamiento y la práctica científica tanto latinoamericana como europea respecto de los valores que conformaban ese ethos de las ciencias que describe Merton.

Hacia fines del siglo XIX en los países más industrializados comienza a producirse "una creciente interdependencia de investigación y técnica, que convierte a las ciencias en la primera fuerza productiva" (Habermas, 2007, p. 81). Esta interdependencia de la ciencia y la técnica penetra en los ámbitos institucionales 
de la sociedad, transforma a las propias instituciones y se desmoronan las viejas legitimaciones (Habermas, 2007).

Sin embargo, tal como señala Diego Hurtado, en ese período de conformación de los Estados-nación latinoamericanos y de institucionalización de las ciencias,

...los vínculos de dependencia con Europa jugaron un papel protagónico en la asimilación de la práctica científica, a través de la común aceptación del "carácter universal del conocimiento científico". Este proceso decisivo de asimilación de la ciencia como práctica social se canalizó a través de una ideología universalista que confundió la estabilidad de los productos finales de la actividad científica -teorías, leyes, conceptos, eficacia técnica- con el supuesto universalismo de la propia práctica de producción de conocimientos. (Hurtado, 2010, pp. 22-23)

Y en este momento es cuando el pensamiento científico liberal de América Latina, comienza a configurar ciertas representaciones que lo diferencian sustancialmente de las nociones predominantes del escenario al que aspiraba emular. Por ejemplo, a fines de la década de 1940, el matemático e historiador de la ciencia argentino José Babini, al describir el período posterior a la crisis política de Argentina de 1890, menciona que:

...se produce en el proceso científico un estancamiento, vale decir una decadencia [...] se produce un incremento de las actividades técnicas en pos de un afán utilitario y de un interés material, que pospone o impide las preocupaciones por la ciencia pura o por la investigación desinteresada. Se cayó así en el error frecuente de adoptar y absorber las aplicaciones de la ciencia antes que la ciencia misma, y el de no advertir que detrás del excitante esplendor del progreso industrial y técnico se oculta el trabajo científico puro y desinteresado, que en gran medida ha contribuido a ese progreso material. (Babini, 1949, pp. 125-126)

La lectura que realiza José Babini sobre la crisis económica argentina de 1890, deja entrever su propia noción de la relación de las ciencias con la sociedad, basada en valores de pureza y desinterés que ya no estaban presentes en la década de 1940 en diversos países europeos o en EEUU, por lo que ya no se trata de una importación de los valores vigentes, sino de la reconfiguración de ciertas nociones del liberalismo científico de décadas anteriores, que reivindicaban la autonomía y la pureza de la práctica científica, y consideraban como "decadencia" científica cualquier grado de interdependencia con su entorno.

Marcuse, al poner en discusión la visión de la industrialización y del capitalismo presente en la obra de Max Weber, plantea que

Su teoría de una ciencia que en el interior de sí misma estaría libre de todo valor, se reveló como lo que era en la práctica: un intento de "liberar" a la ciencia para la aceptación de valores represivos, cuyo origen se encuentra fuera de la ciencia. [...] el concepto de neutralidad, o más bien de impotencia científica frente a los valores e ideales, es insostenible. La pura concepción filosófica y sociológica, al margen de los valores, se convierte en su propio desarrollo en una crítica de los valores; e inversamente, conceptos científicos puros y vacíos de todo valor revelan su propio sistema de valores ocultos.

Mientras que para Marcuse la pureza, la neutralidad, el desinterés, la universalidad son conceptos vacíos que revelan un "sistema de valores ocultos", para Laclau (1996), ese vacío no se repone con valores ocultos, sino que el contenido que vayan a simbolizar "no puede ser determinado ni por un análisis de lo particular en sí mismo ni de lo universal. La relación entre los dos depende del contexto del antagonismo y es, en el sentido estricto del 
término, una operación hegemónica" (Laclau, 1996, p. 15). Estos "significantes vacíos" que define Laclau, tan presentes en el pensamiento científico liberal de América Latina, van a ir adaptando su contenido sobre la base de la negación de aquello a lo que se oponen en cada contexto.

Al producirse la gran crisis internacional de 1930, se redujo sustancialmente la capacidad de importación de los países de América Latina. El núcleo principal de las actividades manufactureras estaba constituido por industrias de terminación de artículos de consumos importados y algunas de estas empresas fueron las que comenzaron a tratar de producir sustitutos locales de algunos ingredientes importados (Furtado, 1985). A partir de la década de 1940, para cuando este proceso de "industrialización por sustitución de importaciones" comienza a cobrar fuerza, diversos organismos internacionales como las Naciones Unidas, la Organización de Estados Americanos, el Banco Interamericano de Desarrollo, e instituciones públicas y privadas de los países industrializados, realizaron un "intenso esfuerzo" para incrementar la capacidad científica y tecnológica de los países de América Latina. Dentro de las actividades incluían "las donaciones y préstamos especiales para equipamiento científico, los subsidios para proyectos específicos de investigación, el envío de personal calificado para participar en la formación de nuevo personal o asesorar en la formulación de la política científica, el otorgamiento de becas para perfeccionamiento en el exterior, etc." (Herrera, 2011, p. 151).

Sin embargo, si bien este tipo de asistencia permitió mejorar el equipamiento de muchos centros de investigación, especialmente las universidades, "el análisis más superficial indica que, en términos generales, se puede hablar casi de un completo fracaso" (Herrera, 2011, p. 152). Entendemos que ese esfuerzo parece haber omitido la cultura científica local que proclamaba la "autonomía" y "pureza" de las ciencias, que ya habían sido dejadas de lado en Europa y EEUU con los procesos de industrialización y desarrollos tecnológicos.

De hecho, en la década de 1970, mientras que en Francia, Inglaterra y EEUU la relación entre la inversión en I+D y la investigación básica era de 9 a 1, y para el resto de Europa occidental era de 4 a 1; en América Latina, por el contrario, esto se invertía y tal como menciona Amílcar Herrera: "si bien no se dispone de datos precisos al respecto, se puede estimar que el subsistema de investigación básica insume un monto de inversiones superior al que se destina a investigación aplicada y de desarrollo" (Herrera, 2011, p. 153).

Esta interdependencia dinámica entre las ciencias y la sociedad que postulaba Merton desde la sociología de las ciencias, comienza a ser problematizada a partir de la década de 1960, con las obras Verdad y método de Gadamer, Industrialización y Capitalismo en Max Weber y El hombre unidimensional de Marcuse, retomadas y discutidas por Habermas en Ciencia y técnica como "ideología", que retroalimentaron las movilizaciones estudiantiles europeas de 1968, como así también la vasta producción latinoamericana de Jorge Sabato, Thomas Moro Simpson, Mario Bunge, Amílcar Herrera, Alfredo Monza, Félix Moreno, Oscar Varsavsky, Natalio Botana, Celsio Furtado, Osvaldo Sunkel, José Leite Lopes, entre tantos otros. Estas nuevas miradas, que proponían otras formas de concebir la relación entre las ciencias y la sociedad, fueron cruelmente desarticuladas y perseguidas por las dictaduras militares que atravesaron el continente entre las décadas de 1960 y 1980.

Como veremos más adelante, medio siglo después, las políticas de evaluación de la producción científicotecnológica que se han implementado en las últimas décadas en varios países de América Latina, responden a las mismas lógicas que primaron en las comunidades científicas liberales de los años 1960 y 1970, aún más acentuadas y formalizadas. 


\section{La industrialización del sistema de comunicación de las ciencias}

Tal como describe Bernal, el efecto obvio e inmediato del nuevo entorno europeo de industrialización de la década de 1940 "es el aumento en el volumen de resultados publicados. Las publicaciones de las sociedades científicas se han duplicado y triplicado en tamaño, y sus tesoreros, en muchos casos, tienen dificultades para compensar el consiguiente gasto adicional" (Bernal, 1939, p. 67).

Siguiendo la tradición de los siglos anteriores, en la Europa de entreguerras, si bien se obtenían ciertos subsidios gubernamentales, el costo de publicar un trabajo corría por cuenta de quien realizaba la investigación y deseaba publicarla. Según Bernal, muy pocas revistas eran comerciales, la mayoría eran editadas por sociedades científicas, las cuales gastaban casi todos sus recursos en la edición y distribución de las revistas y rara vez podían destinar fondos para investigación. Quien investigaba debía pagar también el costo de las revistas y los libros que necesitara consultar y las suscripciones a las sociedades científicas. Como estos pagos no solían contabilizar como gastos de laboratorio, significaba destinar entre el 5 y el 10 por ciento del salario. Además, debido al aumento considerable de publicaciones y las dificultades para el acceso, los autores solían enviar hasta 200 reimpresiones de su trabajo a personas seleccionadas, lo que implicaba un gasto adicional significativo (Bernal, 1939, p. 118).

...debería quedar claro que el actual sistema de publicación científica desperdicia tiempo y dinero y es una fuente constante de irritación para los propios científicos. Es cierto que continuamente se están haciendo esfuerzos para mejorarlo. [...] Lo que se necesita es una revisión mucho más drástica de todo el sistema de comunicación científica. (Bernal, 1939, p. 119)

Esa revisión drástica es la que va a abrir las puertas de la industria editorial y el escenario comienza a cambiar al finalizar la Segunda Guerra Mundial. EEUU dominaba la economía mundial con casi dos tercios de la producción industrial del mundo (Hobsbawm, 2010) y apuesta a una elite científico-tecnológica financiada con fondos gubernamentales que, junto al complejo militar-industrial, para 1960, acumulaban un poder desmesurado, como deja entrever el por entonces presidente Dwight D. Eisenhower, en el discurso de cierre de su mandato. Allí expresa que, en la revolución tecnológica de las últimas décadas:

...la investigación se ha vuelto central; también se ha vuelto más formal, compleja y costosa. Una proporción cada vez mayor se lleva a cabo para, por, o bajo la dirección del gobierno federal [...] La perspectiva de dominar a los académicos de la nación a través del empleo federal, la asignación de proyectos y el poder del dinero está siempre presente, y debe considerarse con seriedad. Sin embargo, si la investigación científica y el descubrimiento se respetan como deberíamos, también debemos estar alertas al peligro igual y opuesto de que la política pública pueda quedar cautiva de una elite científico-tecnológica. (Eisenhower, 1961)

Por estos mismos años, el físico nuclear Alvin Weinberg, en su trabajo titulado Impact of Large-Scale Science on the United States (Weinberg, 1961), describe el mecanismo por el cual esa elite científico-tecnológica, financiada por el Estado pero al servicio del sector industrial, presionaba a los congresistas para que se siguieran aprobando los altos porcentajes de financiamiento. Como analizamos en un trabajo anterior (Martinovich, 2020), para poder instalar la ciencia en la agenda pública era necesario inyectar el mercado con "novedades" que fueran factibles de ser retomadas por los medios de comunicación, lo que dio lugar a una "enorme proliferación de escritura científica que, en gran parte, permanece sin leer" (Weinberg, 1961). Este mecanismo consolidó un complejo industrial científico-editorial en aquellos países altamente industrializados, lo que a su vez generó un cambio en 
los modos de producción: un alto porcentaje de las nuevas revistas ya no estaban respaldadas por sociedades científicas, sino que se creaban en las oficinas comerciales de grandes editoriales como Pergamon Press, Springer, Elsevier o Taylor \& Francis con el propósito de absorber la publicación de artículos de diversas instituciones (Fredriksson, 2001). Y es aquí cuando entra en escena la lógica económica industrial del sector editorial que se alinea con los intereses del poder industrial de la Big Science. Las revistas científicas editadas por el sector industrial se tornaron el canal de legitimación "científica" de los grandes intereses comerciales del complejo científico-industrial.

En América Latina, en un documento publicado en 1971 por el Departamento de Asuntos Científicos de la Organización de Estados Americanos, el economista colombiano Félix Moreno mencionaba:

Las tendencias de los esfuerzos de "desarrollo científico-tecnológico" que se realizan actualmente en los países más grandes y medianos de América Latina son marcadamente liberales, preocupados por el aumento cuantitativo de recursos, en esta área (más libros, más abstracts, más patentes, más marcas extranjeras, más know-how extranjero, etc.), completamente acríticos sobre los costos sociales de la introducción de esas tecnologías, y sin un propósito claro de poner al servicio de las inmensas clases marginadas, ese "prometeo desencadenado" que es la tecnología actualmente. (Moreno, 2011, p. 382)

Si bien en la década de 1970, también se había producido en EEUU una enorme proliferación de escritura científica que, en gran parte, permanecía sin leer, ese crecimiento desmedido era parte de la estrategia de EEUU de invadir la opinión pública para poder conseguir el apoyo parlamentario y seguir sosteniendo los altos porcentajes del PBI destinados a las áreas de investigación (Weinberg, 1961; Martinovich, 2020). Pero en este esquema faltaba un indicador que legitimara y validara este complejo industrial científico-editorial al interior de la comunidad científica internacional. Este es el rol que va a cumplir el "factor de impacto" como estrategia de legitimación internacional: se conforma una base de datos que habilita el ingreso ilimitado de revistas creadas por el complejo industrial científico-editorial, sobre todo de EEUU e Inglaterra, y restringe el ingreso a revistas del resto del mundo editadas bajo modelos productivos con baja participación del sector industrial, para luego contabilizar las citas y evaluar el desempeño como si fuera una muestra representativa de las revistas científicas existentes a nivel mundial.

Se trata de estrategias al servicio de una infraestructura científico-tecnológica orientada fundamentalmente a retroalimentar un sistema económico-productivo como expresión concreta de la racionalidad técnica dominando otras esferas de la vida social. Ahora bien, el pensamiento científico liberal en América Latina se alineaba con la foto del modelo, pero desechaba reproducir a nivel nacional el proyecto económico-político que lo motivaba, por lo tanto, se imitaba la ponderación del volumen de publicación que retroalimentaba el gran complejo industrial científico-editorial, sin vincular esas prácticas a estrategias que abonaran al crecimiento económico-productivo de sus propios países, tal como expresa Félix Moreno:

Ellos defienden una libertad de investigación que es una caricatura, ya que consiste en el derecho de imitar, repetir o complementar las investigaciones de moda de sus colegas en los países desarrollados, y en adquirir méritos en la comunidad internacional mediante publicaciones en las revistas extranjeras, siempre que la investigación sea considerada "interesante" para esos países. (Moreno, 2011, p. 385) 
Desde nuestra perspectiva, solo se imitaba la fachada externa del proceso. La reivindicación de la autonomía de las ciencias y el deseo de integrarse a los núcleos más industrializados, no significaba una aprobación de la maquinaria científico-industrial al servicio de la acumulación capitalista del propio país, sino una reivindicación, por sobre todas las cosas, de un profundo distanciamiento de la realidad nacional.

\section{La paradoja actual}

Hasta los primeros años del siglo XXI, Estados fuertes y débiles, Estados ricos y pobres, nortes y sures, gobiernos de derecha y gobiernos progresistas parecían seguir las reglas del libre mercado y alinear la evaluación de la producción científica a estrategias basadas en indicadores de "calidad" científica creados a medida para asegurar el primado del complejo científico-editorial industrial de los países altamente industrializados.

Estos indicadores, generados por bases de datos como Web of Science y posteriormente Scopus, se utilizaban para evaluar el desempeño de quienes formaban parte del sistema formal de investigación de un país, para la evaluación de las investigaciones, la contratación y el ascenso, la asignación de fondos e incluso la graduación en los programas de doctorado. Los presupuestos que fundamentan estos parámetros de evaluación promovían una legitimación de la razón técnica y un distanciamiento cada vez mayor de esa interdependencia dinámica entre las ciencias y la sociedad.

Cuando Eisenhower alertaba sobre el "peligro igual y opuesto de que la política pública pueda quedar cautiva de una elite científico-tecnológica" (1961) estaba asistiendo en primera persona al primado de esa irracionalidad de la razón técnica que describe Marcuse:

En el desarrollo de la racionalidad capitalista, entonces, la irracionalidad se hace razón, razón como el furioso desarrollo de la productividad, el saqueo de la naturaleza, el incremento de la existencia de mercancías (y su disponibilidad para capas más amplias de la población). Esta razón es irracional porque la mayor productividad, la dominación de la naturaleza y la riqueza social se convierten en fuerzas destructivas, destructivas no sólo metafóricamente, en la venta de los llamados valores culturales más altos, sino literalmente. (Marcuse, 1969, p. 14)

A comienzos del siglo XXI, se abrió un nuevo capítulo con la noción de ciencia abierta que comenzó a cuestionar ciertos aspectos de esa cultura científica que privilegió los intereses del sector tecnológico-industrial en desmedro de los grandes problemas sociales. Si bien los cimientos habían comenzado a resquebrajarse, no se lograban imprimir cambios en las instancias de decisión política. En palabras de Gadamer (2005), la razón técnica del experto seguía desplazando a la razón política.

Organizaciones intergubernamentales como la Comisión Europea, el Parlamento Europeo, el Consejo Europeo, la Organización para la Cooperación y el Desarrollo Económicos (OCDE), las Naciones Unidas, el Banco Mundial, la Unesco, entre otras tantas organizaciones, comenzaron a reconocer la importancia de la ciencia abierta para abordar los grandes desafíos sociales que enfrenta la humanidad, como el cambio climático, las emergencias de salud pública, la producción sostenible de alimentos, la energía eficiente o el transporte inteligente, entre otros (Vicente-Saez \& Martinez-Fuentes, 2018).

Desde que China publicó en 2020 las nuevas políticas de financiamiento y evaluación de la investigación (Zhang \& Sivertsen, 2020), como efecto cascada, varios países europeos y entidades que representan a la Unión Europea han decidido romper con los criterios de evaluación utilizados durante gran parte del siglo XX, para comenzar a delinear políticas más sustentables en términos económicos, que mejoren las formas en que se evalúan los 
resultados de la investigación académica, haciendo un esfuerzo por múltiples vías para hacer que la investigación sea más cooperativa y colaborativa.

Entre los cambios que proponen las nuevas políticas propuestas por el Ministerio de Ciencia y Tecnología y el Ministerio de Educación de China, hay algunos aspectos que desarticulan el esquema mercantilista y promueven el diálogo internacional desde una perspectiva más igualitaria: se implementa un sistema de "obras representativas" que reemplaza la idea de hiperproductividad, se abandona el "factor de impacto" como criterio de evaluación de esa producción y se alienta publicar en mandarín en revistas científicas editadas en China (MoChridhe, 2020; Zhang \& Sivertsen, 2020).

Francia, en julio de 2021, publicó el 2do Plan Nacional para la Ciencia Abierta (MESRI, 2021). Ya en 2019, Frédérique Vidal, ministra de Educación Superior, Investigación e Innovación de Francia, expresaba:

La comunidad científica ha perdido el control sobre el sistema editorial. Sin embargo, es un sistema esencial para el correcto funcionamiento de la ciencia. [...] Es fundamental avanzar hacia una mayor diversidad y un mayor equilibrio en el panorama editorial. Para desarrollar esta bibliodiversidad, decidí crear un fondo de ciencia abierta. [...] Francia contribuirá así a la reinversión del control del sistema editorial por parte de la comunidad científica. (MESRI, 2019)

De hecho, el Consejo Europeo de Investigación, que distribuye 2.400 millones de euros para financiar proyectos de investigación a científicos y académicos de la Unión Europea, anunció a mediados de 2021, la modificación de los criterios de evaluación para el otorgamiento de los fondos, desestimando las métricas corporativas como el "factor de impacto", asumiendo que el contenido científico de un artículo es mucho más importante que las métricas de publicación o la identidad de la revista en la que fue publicado.

En los Países Bajos, en el mes de junio de 2020, la Universidad de Utrecht expresó públicamente su decisión de no tener en cuenta el factor de impacto como medida estándar del éxito científico, en todas las decisiones de contratación y promoción. Según Paul Boselie, "se ha convertido en un modelo muy dañino que va más allá de lo que es realmente relevante para la ciencia y lo que debería promover la ciencia", proponiendo un mayor compromiso con el trabajo en equipo y con la ciencia abierta (Woolston, 2021).

La paradoja es que mientras ciertos países europeos han adoptado estas nociones para generar políticas públicas que promuevan un cambio en la cultura científica y limiten ciertas prácticas monopólicas, en América Latina se ha recorrido el camino inverso, reforzando sistemas de evaluación de la producción científica que reducen la noción de impacto científico a las métricas de citación, retroalimentando los sistemas de legitimación del sector industrial científico-editorial, no solo en la evaluación de la producción, sino en la publicación y distribución de esa producción, desvalorizando los ecosistemas conceptuales y teóricos regionales y el sistema de comunicación de las ciencias (Alperin \& Rozemblum, 2017; Farias et al., 2017; Gómez-Morales, 2018; Vasen \& Lujano Vilchis, 2017; Martinovich, 2020).

Sin embargo, cuando analizamos el recorrido del pensamiento científico liberal de América Latina desde las primeras décadas del siglo XX ¿qué es lo que ha cambiado? Entendemos que no mucho. Desde nuestra perspectiva, se continúa imitando la fachada externa de un proceso de legitimación que tiene otros intereses. En términos discursivos, se creó un relato basado en expresiones, cuyos "significantes vacíos" se fueron adaptando a las nuevas realidades a las que se oponen. 


\section{Conclusiones}

Este breve recorrido por la conformación de la racionalidad técnica que supeditó las políticas públicas a sus propios intereses, penetrando en diversos ámbitos institucionales de la sociedad, desmoronando las viejas legitimaciones (Habermas, 2007), deja entrever que no se trata de una imposición del poder político ni de la lógica industrial por sobre las y los trabajadores de las ciencias, sino que es la propia comunidad científica la que ejerce y reproduce las lógicas dominantes.

Como ya mencionamos, en el caso de América Latina, la reivindicación de la autonomía de las ciencias y el deseo de integrarse a los núcleos más industrializados, no significa una aprobación de la maquinaria científico-industrial al servicio de la acumulación capitalista del propio país, sino una reivindicación, por sobre todas las cosas, de un profundo distanciamiento de la realidad nacional.

Revertir la supremacía de la racionalidad técnica por sobre la razón política, es el gran desafío que tenemos por delante para recuperar una interdependencia dinámica más igualitaria entre las ciencias y la sociedad.

Tal como menciona el economista Paul David, al abordar los orígenes de la ciencia abierta:

Estamos lidiando con el legado de un proceso histórico extenso, intrincado y contingente, que no puede asumirse que haya sido producido por algún sistema subyacente de autoequilibrio y autoregeneración que responde solo a los imperativos de las ciencias y la técnica moderna y, por lo tanto, no requiere mantenimiento ni protecciones políticas. (David, 2008, p. 6)

Las ciencias no se producen en un vacío social, sino que son una actividad socialmente organizada, cuyas prácticas difieren según el financiamiento, la continuidad o discontinuidad de las políticas, la valoración de su entorno social para su desarrollo, pero también de la capacidad de la propia comunidad científica de tornarse actores sociales. Tal como expresa Kleinman y Vallas (2001): "si los actores involucrados son pasivos, es más probable que en la convergencia asimétrica sirva más a los intereses privados que al 'bien público'”.

Las políticas públicas deberían promover un "acto de equilibrio" que implica mucho más que sostener una financiación pública adecuada para las instituciones (David, 2008). El gran desafío actual es, a la luz de las nuevas miradas del pensamiento decolonial, reivindicar nociones más abiertas que privilegien la "ecología de saberes" (Santos, 2017) por sobre el pensamiento unisistémico propio del siglo XX.

Tenemos una deuda con la vasta producción latinoamericana que proponía otras formas de concebir la relación entre las ciencias y la sociedad. En este sentido, cabe rescatar las palabras que Jorge Sabato en 1975: "Mirar nuestra realidad con nuestros propios ojos no es mérito menor, al tiempo que es seguramente el primer paso para modificarla. Sin embargo, no siempre se procede así y es común que se importen esquemas teóricos -o simplemente consignas de moda- que se trata luego de imponer a nuestra situación como un chaleco de fuerza, con olvido o ignorancia de sus características propias" (Sabato, 2011, p. 27)

\section{Referencias Bibliográficas}

Alperin, J. P., \& Rozemblum, C. (2017). La reinterpretación de visibilidad y calidad en las nuevas políticas de evaluación de revistas científicas. Revista Interamericana de Bibliotecología, 40(3), 231-241.

Babini, J. (1949). Historia de la ciencia argentina. Fondo de Cultura Económica. 
Belini, C. (2017). La expansión agroexportadora y los orígenes de la industria moderna, 1880-1914. En Historia de la industria en la Argentina: De la independencia a la crisis de 2001 (pp. 59-115). Sudamericana.

Bernal, J. D. (1939). The social function of science. George Routledge \& Sons.

David, P. A. (2008). The Historical Origins of "Open Science": An Essay on Patronage, Reputation and Common Agency Contracting in the Scientific Revolution. Capitalism and Society, 3(2), 5.

Eisenhower, D. D. (1961). Text of the address by President Eisenhower, broadcast and televised from his office in the White House, Tuesday evening, January 17, 1961. White House Office of Communications. https://www.eisenhowerlibrary.gov/sites/default/files/research/online-documents/farewelladdress/1961-01-17-press-release.pdf

Eisenstein, E. L. (2010). La imprenta como agente de cambio: Comunicación y transformaciones culturales en la Europa moderna temprana. Fondo de Cultura Económica.

Farias, M. R., Storb, B. H., Storpirtis, S., \& Leite, S. N. (2017). Impact Factor: An appropriate criterion for the Qualis journals classification in the Pharmacy area? Brazilian Journal of Pharmaceutical Sciences, 53(3), e01001. https://doi.org/10.1590/s2175-97902017000301001

Fredriksson, E. H. (2001). The Dutch publishing scene: Elsevier and North-Holland. En E. H. Fredriksson (Ed.), $A$ century of science publishing (pp. 61-76). IOS Press.

Freeman, C. (2010). Formal Scientific and Technical Institutions in the National System of Innovation. En B.-Å. Lundvall (Ed.), National systems of innovation: Toward a theory of innovation and interactive learning. Athem Press. https://book4you.org/book/3632113/6d10bd

Furtado, C. (1974). O mito do desenvolvimento econômico ( $3^{\mathrm{a}}$ ed.). Paz e Terra.

Furtado, C. (1985). La nueva dependencia: Deuda externa y monetarismo. Centro Editor de América Latina.

Fyfe, A., Coate, K., Curry, S., Lawson, S., Moxham, N., \& Røstvik, C. M. (2017). Untangling Academic Publishing: A history of the relationship between commercial interests, academic prestige and the circulation of research. Zenodo. https://doi.org/10.5281/zenodo.546100

Gadamer, H.-G. (2005). Verdad y método (11 $11^{\mathrm{a}}$ ed.). Ediciones Sígueme.

Gómez-Morales, Y. J. (2018). Abuso de las medidas y medidas abusivas. Crítica al pensamiento bibliométrico hegemónico. Anuario Colombiano de Historia Social y de la Cultura, 45(1), 269-290. https://doi.org/10.15446/achsc.v45n1.67559

Habermas, J. (2007). Ciencia y técnica como "ideología" (5a ed.). Tecnos.

Herrera, A. O. (2011). Los determinantes sociales de la política científica en América Latina: Política científica explícita y política científica implícita. En J. A. Sabato (Ed.), El pensamiento latinoamericano en la problemática ciencia-tecnología-desarrollo-dependencia (pp. 151-170). Ediciones Biblioteca Nacional.

Hobsbawm, E. (2010). Los años dorados. En Historia del siglo XX (10ª ed., pp. 260-289). Crítica.

Hurtado, D. (2010). La ciencia argentina, un proyecto inconcluso: 1930-2000. Edhasa. 
Jaguaribe, H. (2011). Por qué no se ha desarrollado la ciencia en América Latina. En J. A. Sabato (Ed.), El pensamiento latinoamericano en la problemática ciencia-tecnología-desarrollo-dependencia (pp. 95-115). Ediciones Biblioteca Nacional.

Kleinman, D. L., \& Vallas, S. P. (2001). Science, Capitalism, and the Rise of the "Knowledge Worker": The Changing Structure of Knowledge Production in the United States. Theory and Society, 30(4), 451-492.

Laclau, E. (1996). Emancipation (s). Verso. https://b-ok.lat/book/691945/18c8bf

Marcuse, H. (1969). Industrialización y capitalismo en Max Weber. En La sociedad industrial y el marxismo. Quintana.

Martinovich, V. (2020). Indicadores de citación y relevancia científica: Genealogía de una representación. Dados, 63(2), e20190094. https://doi.org/10.1590/001152582020218

Merton, R. K. (1964). Estudios sobre sociología de las ciencias. En Teoría y estructura social (pp. 615-740). Fondo de Cultura Económica.

MESRI. (2019). Plan national pour la science ouverte: Discours de Frédérique Vidal. https://www.enseignementsup-recherche.gouv.fr/fr/plan-national-pour-la-science-ouverte-discours-defrederique-vidal-49326

MESRI. (2021). Le Plan national pour la science ouverte 2021-2024: Vers une généralisation de la science ouverte en France. enseignementsup-recherche.gouv.fr. https://www.enseignementsuprecherche.gouv.fr/fr/le-plan-national-pour-la-science-ouverte-2021-2024-vers-une-generalisation-de-lascience-ouverte-en-48525

MoChridhe, R. (2020). The hidden language policy of China's research evaluation reform. The Contemporary China Centre Blog. https://blog.westminster.ac.uk/contemporarychina/the-hidden-language-policy-ofchinas-research-evaluation-reform/

Moreno, F. (2011). Modelo para un sistema de producción, selección y transferencia de tecnología. En J. A. Sabato (Ed.), El pensamiento latinoamericano en la problemática ciencia-tecnología-desarrollodependencia (pp. 381-407). Ediciones Biblioteca Nacional.

Sabato, J. A. (2011). Introducción a la primera edición. En J. A. Sabato (Ed.), El pensamiento latinoamericano en la problemática ciencia-tecnología-desarrollo-dependencia (pp. 25-30). Ediciones Biblioteca Nacional.

Santos, B. de S. (2017). Justicia entre Saberes. Epistemologías del Sur contra el epistemicidio. Morata.

Vasen, F., \& Lujano Vilchis, I. (2017). Sistemas nacionales de clasificación de revistas científicas en América Latina: Tendencias recientes e implicaciones para la evaluación académica en ciencias sociales. Revista Mexicana de Ciencias Políticas y Sociales, LXII(231), 199-228.

Vicente-Saez, R., \& Martinez-Fuentes, C. (2018). Open Science now: A systematic literature review for an integrated definition. Journal of Business Research, 88, 428-436.

https://doi.org/10.1016/j.jbusres.2017.12.043

MARTINOVICH Viviana. "Ciencia abierta en América Latina: repensar la interdependencia dinámica entre las 
Weinberg, A. M. (1961). Impact of Large-Scale Science on the United States: Big science is here to stay, but we have yet to make the hard financial and educational choices it imposes. Science, 134(3473), 161-164. https://doi.org/10.1126/science.134.3473.161

Willinsky, J. (2005). The unacknowledged convergence of open source, open access, and open science. First Monday, 10(8). https://doi.org/10.5210/fm.v10i8.1265

Woolston, C. (2021). Impact factor abandoned by Dutch university in hiring and promotion decisions. Nature, 595(7867), 462. https://doi.org/10.1038/d41586-021-01759-5

Zhang, L., \& Sivertsen, G. (2020). The New Research Assessment Reform in China and Its Implementation. Scholarly Assessment Reports, 2(1), 3. https://doi.org/10.29024/sar.15

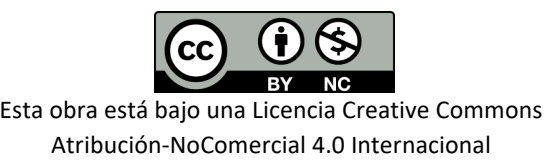

